\title{
Detection of apnoeas, hypopnoeas and arousals by the AutoSet in the sleep apnoea/hypopnoea syndrome
}

\author{
K. Rees*, P.K. Wraith*, M. Berthon-Jones**, N.J. Douglas*
}

Detection of apnoea, hypopnoeas and arousals by the AutoSet in the sleep apnoea/hypopnoea syndrome. K. Rees, P.K. Wraith, M. Berthon-Jones, N.J. Douglas. CERS Journals Ltd 1998.

ABSTRACT: Limited sleep study systems are increasingly being used to diagnose the sleep apnoea/hypopnoea syndrome, but validation is essential and detection of arousal's desirable. One such system (AutoSet) was validated on an event-by-event basis, and the hypothesis that sudden large breaths detected by this system mark arousal from sleep was also examined.

Twenty consecutive patients (apnoea/hypopnoea index (AHI) 39 \pm 6 (SEM)) underwent polysomnography (PSG), which included real-time signals of AutoSet (Version 3.03) scored events. PSG respiratory events were defined using airflow and thoracoabdominal movement and AutoSet events using nasal pressure.

All apnoeas were scored by both systems, but $\mathbf{4 1 \%}$ more hypopnoeas were scored on PSG and these were clinically significant, with $78 \%$ ending in cortical arousal. Twenty per cent of apnoeas and hypopnoeas scored by the AutoSet occurred during wakefulness. Large breaths, defined as a two-thirds increase in ventilation, marked $77 \%$ of respiratory-associated but only $9 \%$ of spontaneous arousals. Large breaths also marked $48 \%$ of "autonomic" arousals following respiratory events without visible electroencephalographic changes. Twenty-seven per cent of large breaths occurred during wakefulness.

This study shows that the AutoSet and the standard polysomnographic approach differ in their detection of hypopnoeas. The AutoSet underdetected hypopnoeas during sleep, but also included some hypopnoeas occurring during wakefulness. Detection of large breaths may potentially be useful for identifying respiratory arousals. Detection of periods of wakefulness may improve the accuracy of the system. Eur Respir J 1998; 12: 764-769.

The prevalence of the sleep apnoea hypopnoea syndrome (SAHS) is reported to be $2-4 \%$ of middle-aged males and $1-2 \%$ of middle-aged females $[1,2]$. It is important that patients are diagnosed correctly and treated, since SAHS is associated with impaired cognitive function [3], increased road traffic accidents [4], and probably with increased cardiovascular and cerebrovascular morbidity and mortality $[5,6]$. Full polysomnography (PSG), which measures sleep, respiratory variables and oxygenation, is still regarded as the gold standard to diagnose the SAHS. However, increasing awareness of the condition has increased patient referral rates, and the high cost of PSG makes limited sleep study systems attractive. This has prompted a series of validation studies to evaluate such limited systems against PSG [7-12].

One limited sleep study system is the AutoSet which, in diagnostic mode, measures airflow from nasal cannulae recording pressure fluctuations in the anterior nares. Previous studies validating this system against simultaneous measurement of PSG report only total overnight data and cannot therefore distinguish the reasons for any discrepancies between the total number of events scored by the two techniques $[7-10,12]$. The present study was designed to examine on an event-by-event basis the accuracy of the ability of AutoSet to detect apnoeas and hypopnoeas as scored on PSG. In contrast to previous studies, this app-
*Respiratory Medicine Unit, University of Edinburgh, Royal Infirmary Edinburgh, UK **ResMed Ltd, North Ryde, Sydney, Australia.

Correspondence: N.J. Douglas

Respiratory Medicine Unit

University of Edinburgh

Royal Infirmary Edinburgh

Lauriston Place

Edinburgh

EH3 9YW

UK.

Fax: 441315363255

Keywords: Arousal

AutoSet

polysomnography

sleep apnoea/hypopnoea

Received: January 191998

Accepted after revision July 81998

Study supported by ResMed Ltd. Conflict of interest: N.J. Douglas is an advisor to ResMed Ltd. roach can identify whether or not thresholds for identification differ and whether or not many events are being scored by this system during wakefulness.

Most limited sleep study systems do not give information about the extent of sleep fragmentation, which is an important correlate of daytime function in SAHS patients $[13,14]$. Nonelectroencephalographic (EEG) measures of arousal have been proposed and, indeed, may be more sensitive measures of sleep fragmentation than EEG recording. These include changes in the beat-to-beat blood-pressure profile $[15,16]$ and in pulse transit time [17]. There are, however, changes in respiratory patterns which occur with arousal, particularly the increased volume of the postapnoeic breath [18, 19]. This study, therefore, examined whether sudden increases in ventilation, as measured by the AutoSet system, can be used as a non-EEG marker of arousal in patients with SAHS.

\section{Methods}

Twenty consecutive males undergoing clinical sleep studies for suspected SAHS were studied. The mean \pm SD age of this group was 48 \pm 11 (range 29-70) yrs, body mass index $31 \pm 5 \mathrm{~kg} \cdot \mathrm{m}^{-2}$, and mean apnoea/hypopnoea index (AHI) according to PSG 39 \pm 26 (range 8-114) events.h slept ${ }^{-1}$. 


\section{Measurements}

Polysomnography. Each patient underwent a single night of PSG using standard techniques [20, 21]. Central and frontal EEG (C3-C4, CZ-PZ, F3-FIP1, F4-FP2), two electro-occulograms (EOG), submental and left and right tibial electromyograms (EMG) and the electrocardiogram (ECG) were monitored. Respiratory variables included nasal airflow recorded on-line to PSG from the AutoSet system (ResMed UK, Oxford, UK), oral airflow measured by thermistor, thoracoabdominal movement by inductance plethysmography and oxygen saturation (Ohmeda, Essex, UK). Digital arterial beat-to-beat blood pressure was recorded on-line to PSG with an infrared plethysmographic volume-clamp method (Finapres 2300, Ohmeda) in 10 out of 20 patients. The position of the hand during plethysmography was verified by infrared video recording to exclude movement artefacts.

AutoSet (Version 3.03). The AutoSet system was linked to the PSG system and signals of AutoSet-scored apnoeas, hypopnoeas and respiratory irregularities were available on-line to compare event-by-event with PSG-scored events. The AutoSet system in diagnostic mode relies on nasal pressure fluctuations in the anterior nares through standard nasal cannulae. Nasal airflow is assessed (arbitrary units 0-20) from an internal pressure transducer [22] and the pressure versus flow relationship is linearized by software. In contrast to previous versions, software version 3.03 differentiates between apnoeas and hypopnoeas and the apnoea index (AI) and apnoea/hypopnoea (AHI) are detected independently. The final report gives the AI, the $\mathrm{AHI}$ and the respiratory irregularity index (large breaths) per hour of recording.

\section{Definitions}

Polysomnographically defined respiratory events. Apnoeas were defined as a complete cessation of airflow for 10 $\mathrm{s}$ or more. Hypopnoeas were defined as a $50 \%$ reduction in thoracoabdominal movement for $10 \mathrm{~s}$ or more compared with the peak amplitude over a 10 -s period that occurred in the last 2 min [21]. This definition was validated by producing the best agreement with arousals and desaturation [21] rather than with absolute changes in ventilation. All events that were preceded by at least $10 \mathrm{~s}$ of sleep were included in the analysis, even if the subsequent arousal resulted in the epoch being scored as awake.

AutoSet-defined respiratory events. An apnoea was scored if the 2-s moving average ventilation fell below $25 \%$ of the recent average (time constant $100 \mathrm{~s}$ ) for at least $10 \mathrm{~s}$. A hypopnoea was scored if the 8-s moving average ventilation dropped below $50 \%$ of the recent average (time constant $100 \mathrm{~s}$ ) for at least $10 \mathrm{~s}$. This definition was designed to detect $50 \%$ reductions in ventilation and not to correlate with arousals or desaturations. A large breath (respiratory irregularity) was scored if there was a two-thirds increase in the 8-s moving average ventilation over any 15 -s period.

Inspiratory flow limitation was defined from the AutoSet drive signal proportional to the square root of nasal pressure, recorded on-line to PSG and defined as a clear "flattening" of the inspiratory flow time profile for two or more breaths, with a $<50 \%$ reduction in tidal volume or thoracoabdominal movement. Snoring was detected from a microphone at the head of the bed and recorded on to PSG.
Arousals. Cortical arousals were defined as a return of $\alpha$ or $\theta$-rhythm for at least $1.5 \mathrm{~s}$ with an associated transient submental EMG rise [13]. Transient increases in beat-tobeat blood pressure of at least $5 \mathrm{mmHg}$ (avoiding the usual respiratory variation in blood pressure) were marked as autonomic arousals.

\section{Analysis}

All polysomnograms were scored manually using standard criteria [20]. Arousals were scored blind to respiratory events. PSG apnoeas and hypopnoeas were scored without sight of the AutoSet marker channel. Periods of predominantly oral breathing where the AutoSet nasal flow signal was very poor were omitted from the analysis.

The number of apnoeas and hypopnoeas scored by the two systems was compared using the Wilcoxon rank test, Bland and Altman plots [23] and Spearman's correlation analysis. The results are reported as mean \pm SEM.

Apnoeas and hypopnoeas were then compared on an event-by-event basis with those scored on PSG. The number of events scored by the AutoSet during wakefulness was noted.

The association of large breaths (respiratory irregularities), as scored by the AutoSet system with prior respiratory events, and their occurrence spontaneously during sleep and during wakefulness was assessed. The total number of arousals, both cortical and autonomic, marked by a respiratory irregularity were calculated to assess the usefulness of the large breath detector as an alternative measure of arousal.
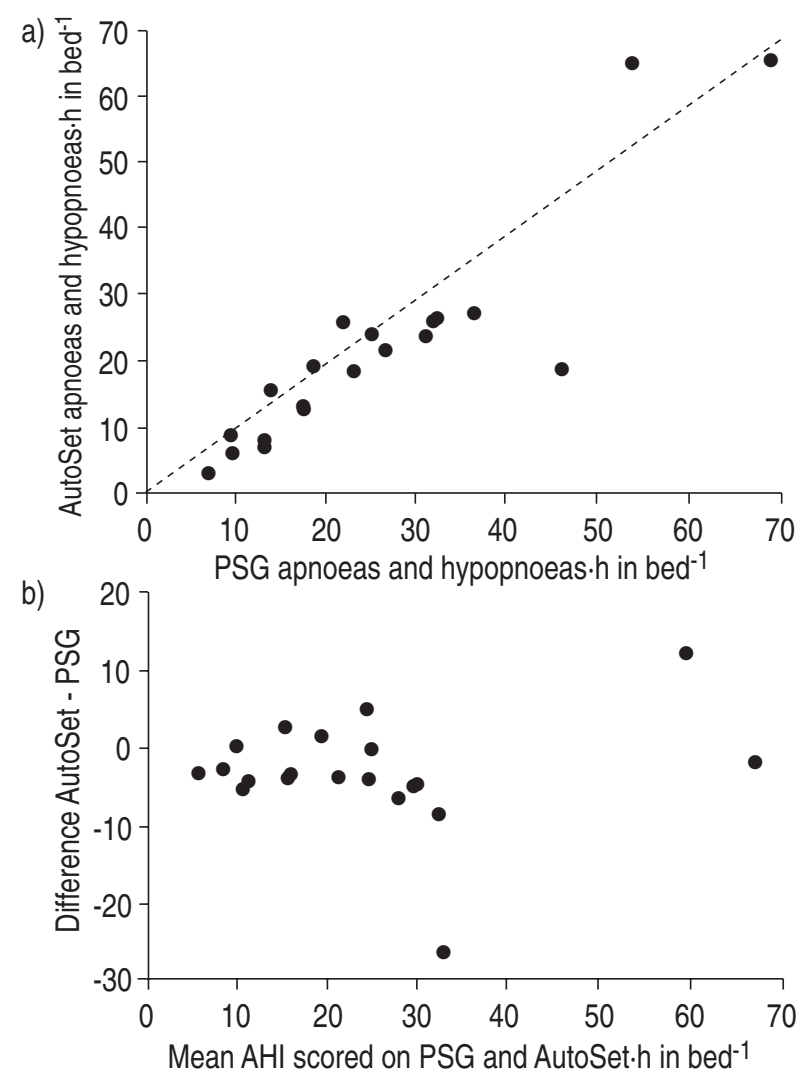

Fig. 1. - a) Scatterplot and b) Bland and Altman plot of the relationship between AutoSet and polysomnography (PSG) in the number of apnoeas and hypopnoeas scored per hour in bed. - - - - : line of identity. AHI: apnoea/hypopnoea index. 


\section{Results}

All 20 studies were technically satisfactory for both PSG and AutoSet signals. The period for comparative ana-lysis of the two systems was reduced in two patients owing to dislodgement of the nasal prongs and prolonged oral breathing. However, in these two cases there was adequate study time in which all signals were technically satisfactory and these patients were not excluded (minimum satisfactory nasal flow signal $193 \mathrm{~min}$ ). The group mean time in bed was $457 \pm 16$ min and total sleep time on PSG $306 \pm 19$ min (range 118-430 min).

Total data comparison between AutoSet and polysomnography for apnoeas and hypopnoeas

There was a good correlation between the number of apnoeas and hypopnoeas per hour in bed scored by the two systems (Spearman's correlation $r=0.9, \mathrm{p}<0.001$, fig. 1a). The AutoSet tended to label a lower number of apnoeas and hypopnoeas with a mean difference of -3.1 apnoeas and hypopnoeas per hour in bed compared with PSG (limits of agreement \pm 2 SD, $+11.2--17.4$; fig. 1b). The AHI.h in bed ${ }^{-1}$ was significantly higher when scored on PSG (PSG 25 \pm 4 , AutoSet 22 $\pm 4, \mathrm{p}=0.025$ ). Similarly, the AHI.h asleep ${ }^{-1}$ as scored on PSG was significantly higher than the number of apnoeas and hypopnoeas per hour in
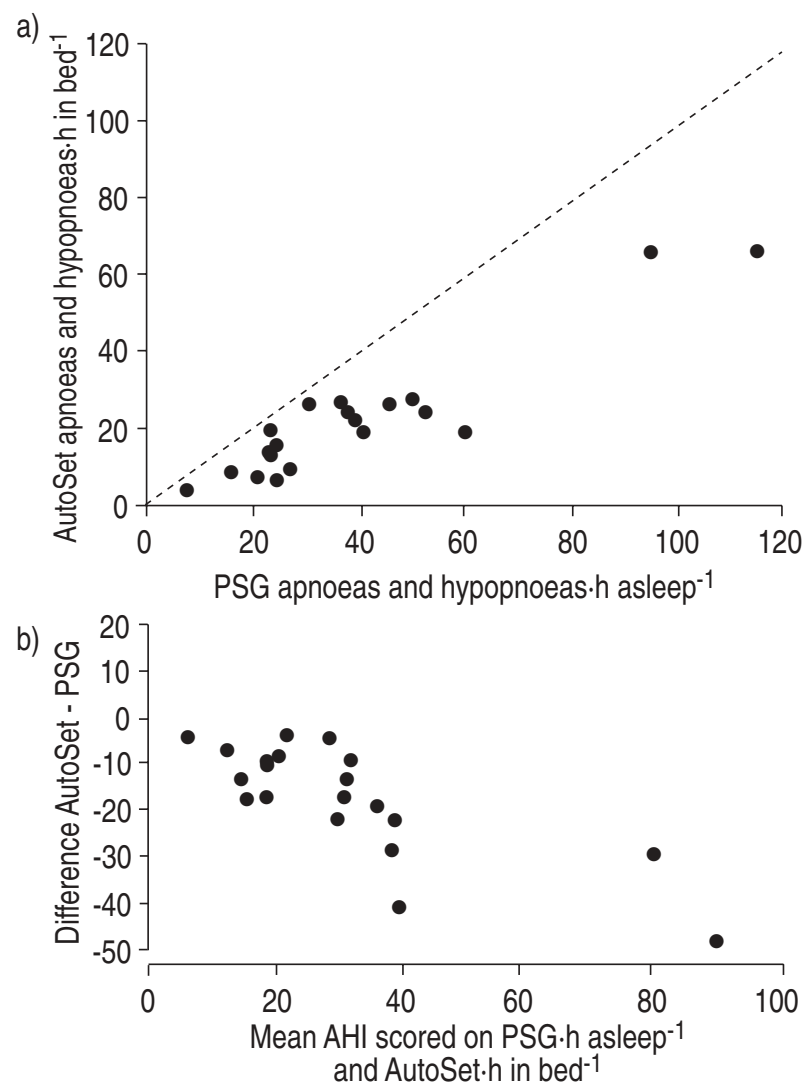

Fig. 2. - a) Scatterplot and b) Bland and Altman plot of the relationship between the number of apnoeas and hypopnoeas scored by the AutoSet per hour in bed (AutoSet nasal apnoea/hypopnoea frequency) and the number of apnoeas and hypopnoeas scored on polysomnography (PSG) per hour of sleep (PSG apnoea/hypopnoea index (AHI)). - . - - : line of identity. bed as scored on the AutoSet system (PSG 39 \pm 6 , p< 0.001), although the PSG AHI and AutoSet nasal apnoea/ hypopnoea frequency were significantly correlated (Spearman's correlation $r=0.8, p<0.001$; fig. $2 a$ ). Figure $2 b$ shows the Bland and Altman plot of PSG AHI $\cdot h$ asleep ${ }^{-1}$ against the AutoSet nasal apnoea/hypopnoea frequency.h in bed ${ }^{-1}$. In all subjects the AutoSet yielded a lower frequency of apnoeas and hypopnoeas than the PSG.

The study also examined the number of events scored by manual analysis of the AutoSet-derived signal proportional to the square root of nasal pressure (hypopnoeas defined as a $50 \%$ reduction in the signal and apnoeas as a complete cessation of the signal) without sight of thoracoabdominal movement or the AutoSet marker channel, and compared this to AutoSet automatic analysis and manual PSG scoring using thoracoabdominal movement. The group mean number of apnoeas plus hypopnoeas scored per night when examining only the nasal pressure signal was $169 \pm$ 27 , compared with $137 \pm 25$ for automatic AutoSet scoring $(\mathrm{p}=0.002)$ and $189 \pm 25$ events.night ${ }^{-1}$ for manual PSG scoring from thoracoabdominal movement and the nasal pressure signal $(\mathrm{p}=0.002)$.

Event-by-event comparison between AutoSet and polysomnography for apnoeas and hypopnoeas

The AutoSet scored all apnoeic events that were scored on PSG (table 1, fig. 3a). However, AutoSet gave lower hypopnoea counts, with $41 \%$ more hypopnoeas detected using the PSG thoracoabdominal movement definition rather than the AutoSet nasal flow definition. These hypopnoeas unscored on the AutoSet were clinically significant, as $78 \%$ ended in cortical arousal. Most of these unscored hypopnoeas $(79 \%)$ were, however, marked by the AutoSet large breath detector (fig. 3b). This decreased recognition of hypopnoeas explains the outlier on figure $1 \mathrm{~b}$, where only $37 \%$ of hypopnoeas scored on PSG were detected by the AutoSet system. The group mean number of apnoeas and hypopnoeas scored by the AutoSet that occurred during wakefulness was $20 \pm 4 \%$, this varied considerably among patients (range 2-74\%).

Table 1. - Event-by-event comparison of AutoSet and polysomnography (PSG)

\begin{tabular}{|c|c|c|c|c|}
\hline & \multicolumn{2}{|c|}{$\begin{array}{l}\text { Events scored } \\
\text { by both PSG } \\
\text { and AutoSet }\end{array}$} & \multicolumn{2}{|c|}{$\begin{array}{l}\text { Events scored } \\
\text { by PSG but } \\
\text { not by AutoSet }\end{array}$} \\
\hline & $\%$ & Range & $\%$ & Range \\
\hline Apnoeas & 100 & & - & \\
\hline Hypopnoeas & $59 \pm 4$ & 26-93 & $41 \pm 4$ & $8-74$ \\
\hline $\begin{array}{l}\text { Associated with } \\
\text { cortical arousal \% } \\
\text { Associated with AutoSet }\end{array}$ & $83 \pm 2$ & $45-100$ & $78 \pm 3$ & $46-100$ \\
\hline large breath \% & $89 \pm 2$ & $65-100$ & $79 \pm 3$ & $63-100$ \\
\hline
\end{tabular}

Comparison of the group mean ( \pm SEM) percentage and range of values for the 20 subjects of apnoeas and hypopnoeas scored by both PSG and the AutoSet system, and the percentage of events scored by PSG but not by the AutoSet. The association of AutoSet scored and unscored hypopnoeas with cortical arousal and the AutoSet large breath (respiratory irregularity) marker are also shown. 


\section{Large breath detection as a marker of arousal}

Most of the large breaths scored by the AutoSet system (67\%) occurred following respiratory events (apnoeas, hypopnoeas, inspiratory flow limitation (IFL)/snoring; table 2 ) and $51 \%$ had associated cortical arousal. Of the remaining large breaths scored by the AutoSet, 27\% occurred during wakefulness, $2 \%$ marked spontaneous arousals and $3 \%$ occurred spontaneously during sleep (no arousal or preceding respiratory event).

There was a significant relationship between the total number of large breaths and the total number of cortical arousals (fig. 4). The relationship between these variables was improved when large breaths scored during wakeful-

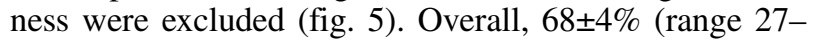
$97 \%$ ) of the total number of cortical arousals (respiratory and spontaneous) scored on PSG were detected by a large breath. Most of the cortical arousals scored on PSG $(85 \pm 3 \%)$ were respiratory related (preceded by apnoeas, hypopnoeas, IFL/snoring) and $15 \pm 3$ were spontaneous. Of the total respiratory arousals, $77 \pm 3 \%$ (range $52-97 \%$ ) were marked by the large breath detector and only $9 \pm 2 \%$ (range $0-33 \%$ ) of the spontaneous arousals were marked by a large breath. Of the total blood pressure rises preceded by a respiratory event and/or associated with cortical arousal, $65 \pm 4 \%$ (range 48-87\%) were associated with a large breath; $31 \pm 3 \%$ (range $20-42 \%$ ) of these induced transient increases in blood pressure were not associated with cortical arousal, but were preceded by a respiratory event and were termed autonomic arousals. Of these autonomic arousals, $48 \pm 6 \%$ (range $24-80 \%$ ) were marked by the large breath detector.

a)

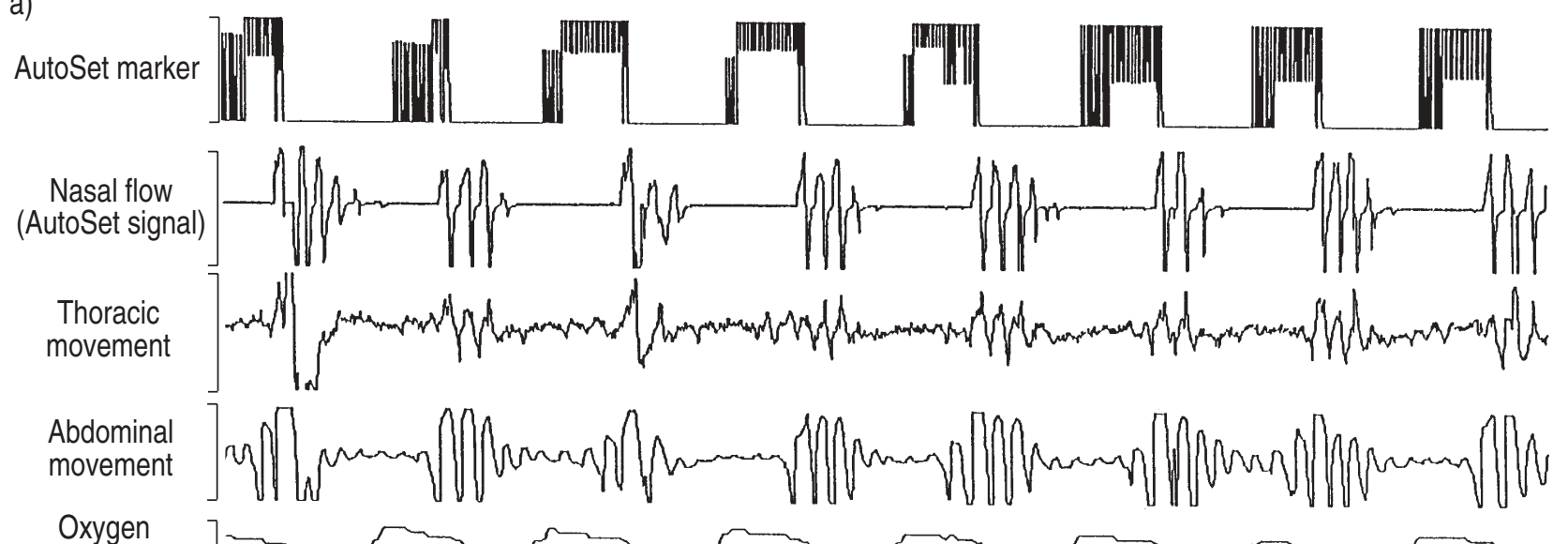

b)

saturation
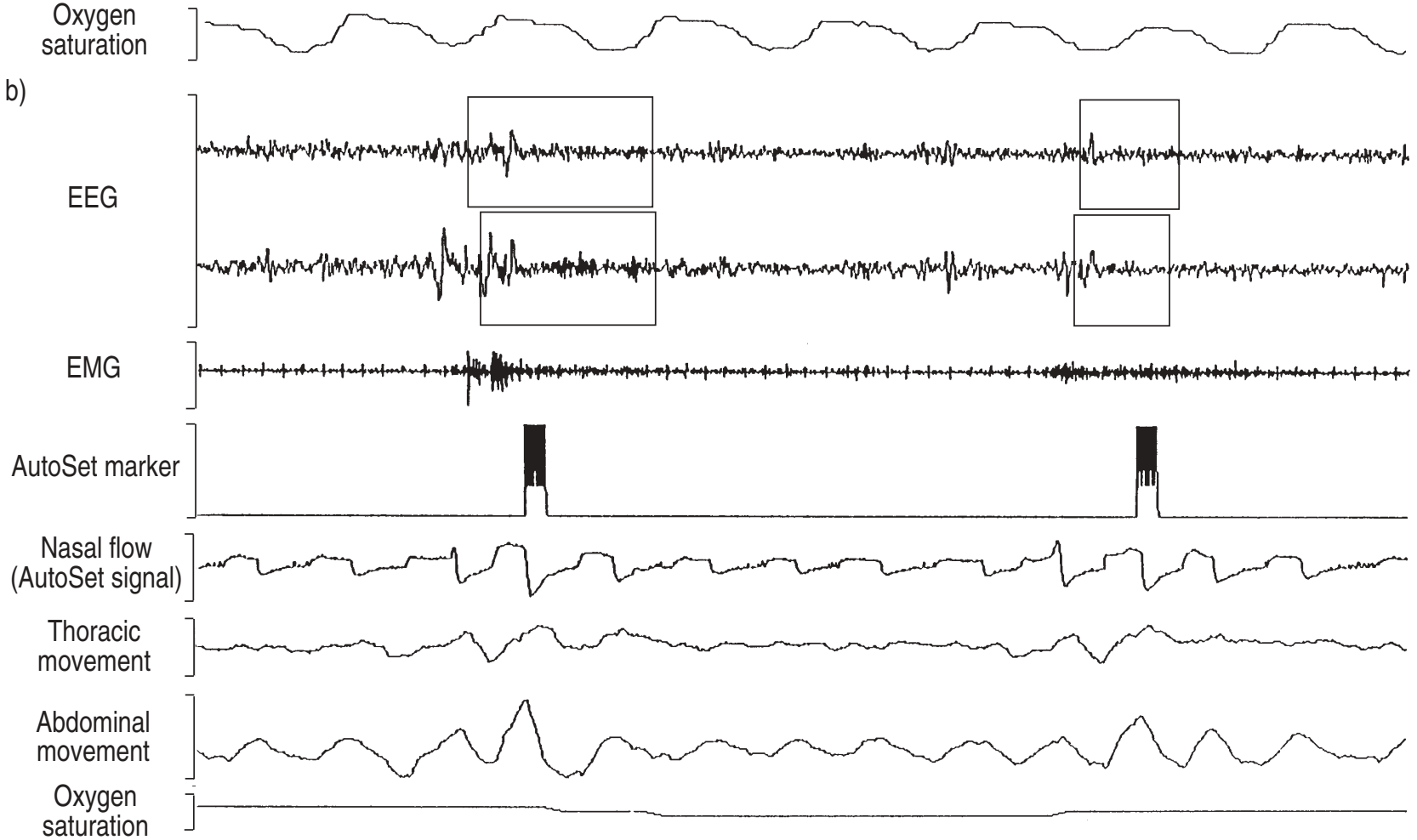

Fig. 3. - a) Example of obstructive apnoeic events correctly scored by the AutoSet system in a severe patient. b) Example of hypopnoeic periods which are not scored by the AutoSet but are scored by polysomnography. There is a $50 \%$ reduction in thoracoabdominal movement but the reduction in airflow is insufficient to be scored by the AutoSet. These events are marked by an AutoSet large breath and are terminated by cortical arousal as marked by the boxes on the electroencephalogram (EEG) channel. EMG: electromyogram. 
Table 2. - Association of AutoSet large breaths (respiratory irregularities) and polysomnographically (PSG) scored events

\begin{tabular}{lcc}
\hline Event & \multicolumn{2}{c}{ Total large breaths \% } \\
\cline { 2 - 3 } & Mean \pm SEM & Range \\
\hline $\begin{array}{l}\text { During wakefulness } \\
\text { Following respiratory events with cortical } \\
\quad \text { arousal }\end{array}$ & $27 \pm 4$ & $(4-69)$ \\
$\begin{array}{l}\text { Following respiratory events no cortical } \\
\quad \text { arousal }\end{array}$ & $51 \pm 3$ & $(22-72)$ \\
With spontaneous (nonrespiratory) arousals & $16 \pm 2.4$ & $(0.3-39)$ \\
Occurring spontaneously during sleep & $3 \pm 0.6$ & $(0-10)$ \\
\hline
\end{tabular}

The association is shown of AutoSet large breaths (respiratory irregularities), respiratory events and cortical arousals as scored on PSG, and the occurrence of large breaths during wakefulness and spontaneously during sleep. Results are expressed as a percentage (group mean \pm SEM) of the total number of large breaths scored by the AutoSet. The range of values for the 20 subjects is shown.

\section{Discussion}

This study shows that the AutoSet detects all apnoeas and most hypopnoeas scored on PSG. These facilities may be of considerable value in clinical practice but the limitations of the device need to be clearly understood.

Many and varying definitions of hypopnoeas are used in the sleep literature [21, 24]. Furthermore, there are different philosophies behind what constitutes a hypopnoea. A hypopnoea may be defined as a diminution in minute ventilation below a predetermined threshold and the AutoSet was so designed. Most sleep studies are currently performed without the facility to measure minute ventilation accurately but instead a semiquantitative, or nonquantitative, assessment is made, either from thoracoabdominal movement or less accurately from the temperature or composition of exhaled gas [21]. Researchers using such semiquantitative definitions have determined what constitutes a significant hypopnoea by obtaining the best agreement between hypopnoeas and either arousals or desaturations [21]. As expected, these two different approaches, i.e. arbitrary quantitative ventilatory changes and correlation with short-term outcomes, produce differing results. Indeed, event-by-event analysis of the two systems reveals that many thoracoabdominal movement hypopnoeas record-

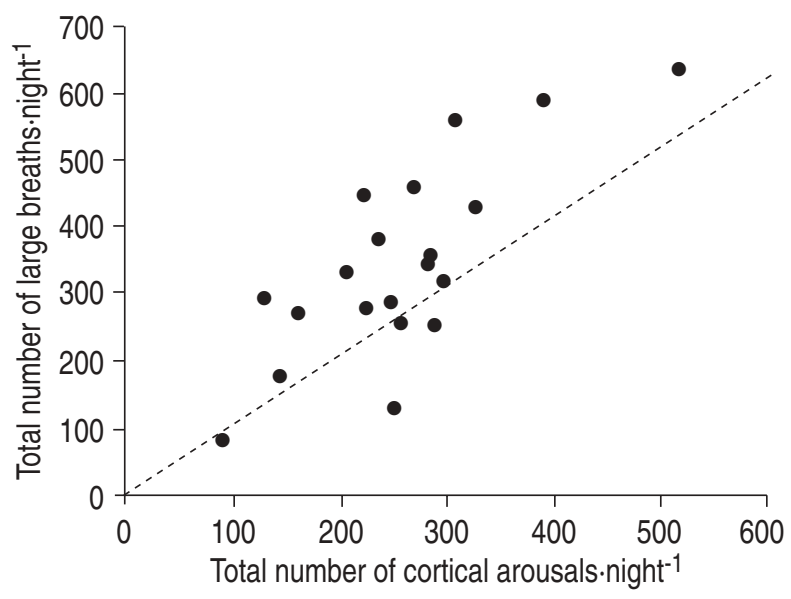

Fig. 4. - Relationship between the total number of AutoSet large breaths (respiratory irregularities) and cortical arousals (respiratory and spontaneous) as measured by polysomnography per night. Spearman's correlation: $r=0.61, p=0.004$. - - - - : line of identity.

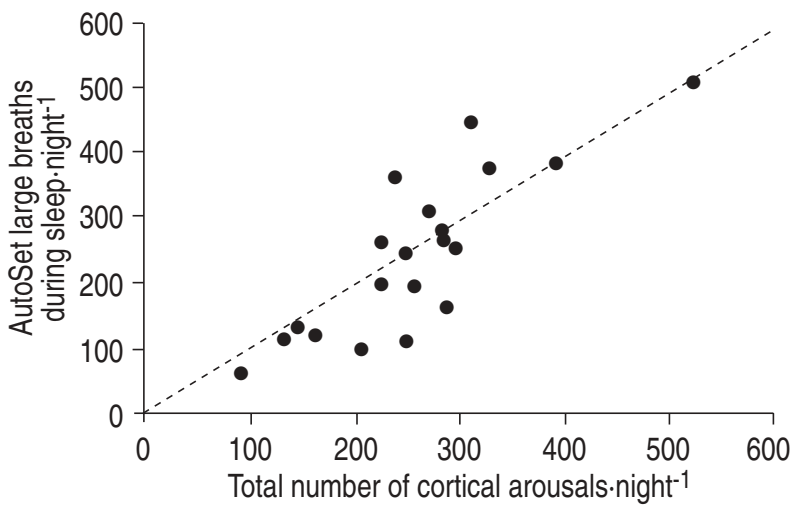

Fig. 5. - Relationship between the total number of AutoSet large breaths scored during sleep (excluding wake events) and cortical arousals as measured by polysomnography per night. Spearman's correlation: $\mathrm{r}=0.78, \mathrm{p}<0.001$. - - - - : line of identity.

ed on PSG and associated with arousals are not detected by the AutoSet algorithm. In all patients the AutoSet apnoea/hypopnoea frequency during sleep was less than that scored on PSG. Researchers using the AutoSet must be aware of this difference. However, approximately $20 \%$ of hypopnoeas scored by the AutoSet occurred during wakefulness and inclusion of these in a total overnight score partially compensated for the underrecognition of hypopnoeas by this system.

It is of interest that the number of apnoeas and hypopnoeas scored by manual analysis of the nasal pressure signal was slightly but significantly lower (20 events. night ${ }^{-1}$, $\mathrm{p}=0.002$ ) than by manual scoring from nasal pressure plus thoracoabdominal movement. This implies that some hypopnoeas are detected by a $50 \%$ decrease in thoracoabdominal movement but do not result in a $50 \%$ decrease in "flow", as derived by nasal pressure. This discrepancy will, of course, contribute to the difference in events scored by PSG and the AutoSet.

Previous studies comparing the AutoSet system with PSG are difficult to compare with the present study. Some studies only compared PSG AHI with AutoSet apnoea/ hypopnoea frequency per hour in bed and, therefore, the denominators differed [12], others used earlier versions of software $[7,8]$ and others thermal definitions of hypopnoeas, which are less quantitative $[21,25]$ and correlate less well with arousals and desaturations than inductive plethysmographic hypopnoea definitions [21]. A study using a nasal mask and pneumotachograph to define hypopnoeas found, as in the present study, that the AutoSet underestimates hypopnoeas [9].

The AutoSet respiratory irregularities (large breaths), detecting abrupt increases in ventilation, occurred most frequently following respiratory events; however, many occurred during periods of wakefulness $(27 \%)$. The association between hyperventilation following respiratory events and the presence of cortical arousal has been shown previously $[18,19]$. In normal subjects ventilation increases substantially following airway occlusion in nonrapid eye movement (NREM) sleep compared with preocclusion values when occlusions were associated with detectable cortical arousal; where no cortical arousal was detected this effect was significantly reduced [18]. The effect of cortical arousal on the hyperventilation following respiratory events has also been shown in SAHS patients [19]. Two recent studies have also shown the association between 
cortical arousal and increased ventilation in response to nonrespiratory (acoustic) stimulation [26, 27]. Large breaths were associated with $68 \%$ of the total cortical arousals scored, mostly followed respiratory events, and few occurred in association with spontaneous arousals. Spontaneous as well as respiratory-related arousals would be expected to be associated with an increase in ventilation. However, large breaths, as defined by this system, marked relatively few spontaneous arousals. Whilst there is a close association between respiratory cortical arousal and large breaths as detected by this system (fig. 5), further work is required to determine the best threshold for detection before its clinical utility as an arousal detector can be assessed.

Transient changes in the beat-to-beat blood-pressure profile have been proposed as a more sensitive marker of sleep fragmentation than the presence of visible EEG arousal $[15,16]$. Apnoeic events that are not terminated with a detectable EEG arousal are consistently associated with a rise in both systolic and diastolic blood pressure at apnoea termination [16]. A recent study has shown that these "autonomic arousals" are significant in causing daytime sleepiness in normal subjects following sleep fragmentation by acoustic stimuli titrated to produce rises in blood pressure without visible change on the EEG [28]. The AutoSet large breath detector marked $48 \%$ of blood pressure increases associated with respiratory events where no cortical arousal was detected at their termination. Thus, large breaths detect some events that conventional EEG arousal scoring does not, but they are not as sensitive as cardiovascular markers of sleep fragmentation.

The AutoSet system in its diagnostic mode cannot and was not designed to reproduce the results of full polysomnography but to provide a limited "sleep" study system that is superior to oximetry alone $[20,29]$. The relationship between respiratory events scored by the two systems differs because of the differing philosophies behind the definitions of hypopnoea used and the scoring of events during wakefulness; however, if this is recognized the AutoSet can be a useful limited sleep study system. Large breaths were associated with respiratory-related cortical arousals when periods of wakefulness were excluded, but further work is required on the detection threshold. The accuracy of both the respiratory event and arousal detectors would be improved if the system were modified to detect periods of wakefulness.

\section{References}

1. Young T, Palta M, Dempsey J, Skatrud J, Weber S, Badr $\mathrm{S}$. The occurrence of sleep disordered breathing among middle aged adults. $N$ Engl J Med 1993; 328: 1230-1235.

2. Jennum P, Sjol A. Epidemiology of snoring and obstructive sleep apnoea in a Danish population age 30-60. $J$ Sleep Res 1992; 1: 240-244.

3. Engleman HM, Martin SE, Deary IJ, Douglas NJ. Effect of continuous positive airway treatment on daytime function in sleep apnoea/hypopnoea syndrome. Lancet 1994; 343: 572-575

4. Findley U, Umversat ME, Surratt PM. Automobile accidents involving patients with obstructive sleep apnea. Am Rev Respir Dis 1988; 138: 337-340.

5. Partinen M, Jamieson A, Guilleminault C. Longterm outcome for obstructive sleep apnea syndrome patients: mortality. Chest 1988; 94: 1200-1204.

6. He J, Kryger MH, Zorick FJ, Conway W, Roth TH. Mortality and apnea index in obstructive sleep apnea. Chest 1988; 92: 9-14.
7. Gugger M, Mathis J, Bassetti C. Accuracy of an intelligent CPAP machine with inbuilt diagnostic abilities in detecting apnoea: a comparison with polysomnography. Thorax 1995; 50: 1199-1201.

8. Bradley PA, Mortimore IL, Douglas NJ. Comparison of polysomnography with ResCare Autoset in the diagnosis of the sleep apnoea/hypopnoea syndrome. Thorax 1995; 50: 1201-1203.

9. Fleury B, Rakatonanahary D, Hausser-Hauw C, Lebeau B, Guilleminault C. A laboratory validation study of the diagnostic mode of the AutoSet system for sleep related respiratory disorders. Sleep 1996; 19: 502-505.

10. Kiely JL, Delahunty C, Matthews S, McNicholas WT. Comparison of a limited diagnostic system (ResCare AutoSet) with polysomnography in the diagnosis of obstructive sleep apnoea syndrome. Eur Respir J 1996; 9: 2360-2364.

11. Lloberes P, Monserrat JM, Ascaso A, et al. Comparison of partially attended night time respiratory recordings and full polysomnography in patients with suspected sleep apnoea/ hypopnoea syndrome. Thorax 1996; 51: 1043-1047.

12. Gugger M. Comparison of ResMed AutoSet (version 3.03) with polysomnography in the sleep apnoea/hypopnoea syndrome. Eur Respir J 1997; 10: 587-591.

13. Cheshire K, Engleman HM, Deary JJ, Shapiro C, Douglas NJ. Factors impairing daytime performance in patients with sleep apnoea/hypopnoea syndrome. Arch Intern Med 1992; 152: 538-541.

14. Martin SE, Engleman HM, Deary IJ, Douglas NJ. The effect of sleep fragmentation on daytime function. Am J Respir Crit Care Med 1996; 153: 1328-1332.

15. Davies RJO, Belt PJ, Roberts SJ, Ali NJ, Stradling JR. Arterial blood pressure response to graded transient arous-al from sleep in normal humans. J Appl Physiol 1993; 74: 1123-1130.

16. Rees K, Spence DPS, Earis JE, Calverley PMA. Arousal responses from apneic events during non-rapid-eye-movement sleep. Am J Respir Crit Care Med 1995; 152: 1016-1021.

17. Pitson D, Chhina N, Knijn S, Van Herwaaden M, Stradling J. Changes in pulse transit time and pulse rate as markers for arousal in normal subjects. Clin Sci 1994; 84: 269-273.

18. Nolan P, O'Donnell J, Deegan P, Regan RG, McNicholas WT. Role of cortical arousal in the ventilatory response to airway occlusion during sleep. Am Rev Respir Dis 1993; 147: A514.

19. Rees K, Spence DPS, Earis JE, Calverley PMA. Ventilatory response to arousal at apnoea termination in obstructive sleep apnoea. Am J Respir Crit Care Med 1994; 149: A305.

20. Douglas NJ, Thomas S, Jan MA. Clinical value of polysomnography. Lancet 1992; 339: 347-350.

21. Gould GA, Whyte KF, Rhind GB, et al. The sleep hypopnea syndrome. Am Rev Respir Dis 1988; 137: 895-898.

22. Berthon-Jones M. Feasibility of a self-setting CPAP machine. Sleep 1993; 16: S120-S123.

23. Bland JM, Altman DG. Statistical methods for assessing agreement between two methods of clinical measurement. Lancet 1986; i: 307-310.

24. Moser NJ, Phillips BA, Berry DTR, Harbison L. What is a hypopnea, anyway? Chest 1994; 105: 426-428.

25. Berg S, Haight JSJ, Yap V, Hoffstein V, Cole P. Comparison of direct and indirect measurements of respiratory airflow: implications for hypopneas. Sleep 1997; 20: 60-64.

26. Carley DW, Applebaum R, Basner RC, Onal E, Lopata M. Respiratory and arousal responses to acoustic stimulation. Chest 1997; 112: 1567-1571.

27. Badr MS, Morgan BJ, Finn L, Toiber FS, Crabtree DC, Puleo DS, Skatrud JB. Ventilatory response to induced auditory arousals during NREM sleep. Sleep 1997; 20: 707-714.

28. Martin SE, Wraith PK, Deary IJ, Douglas NJ. The effect of nonvisible sleep fragmentation on daytime function. Am J Respir Crit Care Med 1997; 155: 1596-1601.

29. Douglas NJ. How to reach a diagnosis in patients who may have the sleep apnoea/hypopnoea syndrome. Thorax 1995; 50: 883-886. 